\title{
Research on Multi-level Distribution Strategy Based on Energy Internet
}

\author{
Fengzhi $\mathrm{Wu}^{1 *}$, Gaofeng $\mathrm{Xu}^{2}$, Ziyi $\mathrm{Qi}^{3}$, Zhi $\mathrm{Qi}^{4}$, Meng Zhang ${ }^{5}$, Rong $\mathrm{He}^{6}$ \\ ${ }^{1}$ Information Science and Manufacturing Engineering, Specialization in Renewable Energy and Environmental Engineering, Ashikaga \\ University, Tochigi, Ashikaga-shi, 326-8558, Japan \\ ${ }^{2}$ Shanghai Urban Construction Vocational College, Shanghai, Shanghai, 201415, China \\ ${ }^{3}$ State Grid Huludao Electric Power Supply Company, Huludao, Liaoning, 125000, China \\ ${ }^{4}$ State Grid Huludao Electric Power Supply Company, Huludao, Liaoning, 125000, China \\ ${ }^{5}$ Nanjing University of Aeronautics and Astronautics, Nanjing, Jiangsu, 210000, China \\ ${ }^{6}$ China Mobil Tietong Corporation Fuzhou Branch, Fuzhou, Fujian 350001, China
}

\begin{abstract}
Smart city energy Internet is to comply with the trend of sustainable energy development, urban power energy as the center, comprehensive utilization of all kinds of energy, especially renewable energy, to achieve interconnection and common optimization. Based on the background of distribution network in Disney Park, this paper studies the regulation, operation and management strategy of distribution network of smart city energy Internet. This paper describes the characteristics of the energy Internet, and then analyzes the key technologies that affect power grid regulation, operation and management. The paper investigated the distribution network construction in Shanghai Disney Park under the background of urban energy Internet pilot region to understand the allocation of distributed energy in the park grid. Through simulation calculation and analysis, this paper puts forward a distribution network regulation and management scheme suitable for the characteristics of energy Internet. In this paper, the study found that with the rapid development of power grid, especially all kinds of distributed energy access, the new lines are becoming more. In a wide range of power grid structure is becoming more and more complex, in order to ensure the reliability of power supply and power supply quality, scientific regulation under the background of urban energy Internet development mode, enhancing the management level of power grid is the inevitable developing trend of power grid.
\end{abstract}

\section{Introduction}

Energy is the premise of contemporary social development, while renewable energy has the characteristics of being inexhaustible, inexhaustible and green, which has attracted the attention of countries around the world [1]. In recent years, China's environmental pollution has become more and more serious, the growth of non-renewable energy has been unable to keep pace with the national economic development, and fossil resources such as oil and coal are increasingly strained [2]. Therefore, China's development model needs to take technological innovation and industrial innovation as the entry point to transform from the traditional rough type to the more simplified, economic and sustainable type [3].

Foreign researches on energy interconnection focus on the content and characteristics of energy interconnection, on-site practice results of energy interconnection, practical significance and composition of energy interconnection, etc., and relevant researches have achieved certain results [4]. In literature [5], the author discusses the characteristics and related control of new energy distribution network under the Internet, and analyzes the characteristics of this type of distribution network from the aspects of basic mode, structure and information requirements. In literature [6], the author builds the basic model of the energy router and proposes that the breakthrough direction of the Internet's energy development is flexible transmission and distribution technology. In literature [7], the author applies complex network theory to the establishment of energy network topology architecture from a macroscopic perspective, and proposes Suggestions for the subsequent research on the design and improvement of energy Internet system. In literature [8], the author discusses the development prospect of flexible transmission and distribution technology in the energy Internet, and proposes two realization schemes for the flexible transmission and distribution technology in the energy network in the future.

Existing studies have recognized that the energy Internet can effectively improve energy use efficiency, and promote the development of energy consumption towards the goal of simplicity and green, and build the energy Internet as a key method to promote energy reform [9]. However, most of the current researches are on the basic forms of typical energy interconnection, discussing 
definitions, technical systems, topological structures and future prospects, but the possible impacts and problems of energy Internet have not been studied from the perspective of power grid regulation, operation and management in the context of energy Internet [10]. This study firstly points out that under the background of urban energy Internet, developing scientific dispatching mode and improving power grid management level are the inevitable trend of power grid development. By analyzing the development demand of power grid, key technologies of energy Internet and domestic power grid regulation and management system, this paper studies the regulation, operation and management strategy of power distribution network in the context of urban energy Internet.

\section{Security Regulation and Management Plan in the Context of Urban Energy Internet}

\subsection{New Problems of Distribution Network Regulation and Management in the Context of Urban Energy Internet}

Combining communication technology and new energy technology, energy Internet emphasizes the coordinated use of all forms of energy, and is an energy ecosystem with electricity as the main form and smart grid as the main body. The integration of multiple distributed power sources into the distribution network has the following impacts on regulation and management:

(1) Increase the uncertainty of distribution network operation

The operation of renewable energy power generation connected to the distribution network greatly increases the uncertainty factors of the distribution network, causing the uncertainty of the voltage and power flow of the network nodes. Therefore, the distribution network regulation and management scheme cannot be established solely on the basis of mean value prediction. In the process of power grid operation, the regulator of distribution network has to pay attention to the access uncertainty of distributed new energy.

(2) Influence system network loss and voltage distribution

When the capacity of distributed power sources such as photovoltaic power generation is relatively small, distributed power sources can reduce the transmission power on transmission and distribution lines, so as to reduce the total line loss of the system and improve the voltage of system nodes. If there is an opposite power flow when a large distributed power supply is supplied, the reverse power flow of the distribution network may be greater than the original line power, resulting in an increase in the overall circuit loss and a decrease in the distribution network operation economy.

(3) Influence the reactive power balance of the main network

Due to the popularization of distributed generation technology, the power factor regulation of distributed power grid is required. Although this operation can support the local reactive power balance of distribution network to a certain extent, the unreasonable distribution of power factor will cause the distribution network to absorb too much reactive power, and may also destroy the reactive power balance of the main network, which will have a negative impact on the structure of the grid and the insufficient reactive capacity.

\subsection{Voltage Calculation of System Nodes after Access to Distributed Energy}

In order to analyze the influence of distributed new energy generation on voltage stability after user side access, the following analysis and calculation is carried out based on the node voltage after distributed power grid connection. The power consumed by the network unit includes the resistance of the current flowing through the unit and the power of equivalent dissipation reactance, as well as the power equivalent dissipation to ground admittance when the voltage is applied to the unit. The power loss of parallel admittance can be ignored because of the low voltage level of distributed power supply. Network unit refers to transmission and distribution lines and transformers. Assuming that the system transmits the power of $\mathrm{S}=\mathrm{P}+\mathrm{jQ}$ to the network, the power lost on the resistance and reactance of the unit is:

$$
\Delta S=\frac{P^{2}+Q^{2}}{V^{2}} \times(R+j X)
$$

When the user-side distributed power supply is connected to the grid, the distributed power supply delivers the power of $\mathrm{S}^{*}=\mathrm{P}^{*}+\mathrm{jQ} \mathrm{Q}^{*}$ to the network, and the power loss on the resistance and reactance of the unit is:

$$
\Delta S^{*}=\frac{\left(P-P^{*}\right)^{2}+\left(Q-Q^{*}\right)^{2}}{V^{2}} \times(R+j X)(2)
$$

From the above equation, it can be seen that $\triangle \mathrm{S}$ is less than $\triangle S^{*}$, and the grid loss can be reduced after the load-side distributed power grid connection. Of course, if the grid connection capacity is too large, the power backfeed may also increase the grid loss.

\section{Case of Distribution Network Regulation and Management under the Background of Smart City Energy Internet}

\subsection{Introduction to the Distribution Network of the Case Park}

The distribution network of Shanghai Disneyland park is used in this paper. The total planning area of Shanghai Disneyland is 24.7 square kilometers, and the Disney Park which has been developed covers an area of 7 square kilometers, focusing on the development of exhibitions, art, retail and other businesses. 


\subsection{Analysis and Calculation Conditions and Parameters of the Distribution Network in the Case Park}

The selected example for this analysis is the $10 \mathrm{kV}$ distribution network of Disney Park. The park is mainly powered by $110 \mathrm{kV}$ Disney Station and $35 \mathrm{kV}$ South Railway Station. All cable lines in the park are used for power supply. Due to short power supply radius and large

Table 1. Calculation parameters of each branch of the case system

\begin{tabular}{cccc}
\hline Number & Branch name & Resistance $(\Omega)$ & Reactance $(\Omega)$ \\
\hline 1 & F9147 \# branch & 0.27 & 0.8 \\
\hline 2 & F9163 \# branch & 0.28 & 1.12 \\
\hline 3 & F9164 \# branch & 0.2 & 0.98 \\
\hline 4 & F9172 \# branch & 0.27 & 0.88 \\
\hline 5 & F9173 \# branch & 0.36 & 1.02 \\
\hline 6 & F9187 \# branch & 0.13 & 0.99 \\
\hline 7 & F9190 \# branch & 0.36 & 0.89 \\
\hline 8 & F9193 \# branch & 0.29 & 0.92 \\
\hline 9 & F9198 \# branch & 0.27 & 0.9 \\
\hline
\end{tabular}

Table 2. Typical daily load data (MW) of the case system

\begin{tabular}{cccccccc}
\hline Time & Load & Time & Load & Time & Load & Time & Load \\
\hline $0: 30$ & 21.94 & $1: 00$ & 23.28 & $12: 30$ & 26.53 & $13: 00$ & 26.48 \\
\hline $1: 30$ & 22.00 & $2: 00$ & 23.46 & $13: 30$ & 26.60 & $14: 00$ & 26.49 \\
\hline $2: 30$ & 22.06 & $3: 00$ & 23.51 & $14: 30$ & 26.74 & $15: 00$ & 26.53 \\
\hline $3: 30$ & 22.09 & $4: 00$ & 23.82 & $15: 30$ & 27.01 & $16: 00$ & 26.60 \\
\hline $4: 30$ & 22.28 & $5: 00$ & 22.65 & $16: 30$ & 27.02 & $17: 00$ & 26.74 \\
\hline $5: 30$ & 22.46 & $6: 00$ & 22.67 & $17: 30$ & 27.10 & $18: 00$ & 27.48 \\
\hline $6: 30$ & 22.52 & $7: 00$ & 22.88 & $18: 30$ & 27.29 & $19: 00$ & 27.53 \\
\hline $7: 30$ & 24.42 & $8: 00$ & 24.74 & $19: 30$ & 27.32 & $20: 00$ & 27.10 \\
\hline $8: 30$ & 24.54 & $9: 00$ & 24.75 & $20: 30$ & 27.37 & $21: 00$ & 27.29 \\
\hline $9: 30$ & 24.55 & $10: 00$ & 24.78 & $21: 30$ & 26.74 & $22: 00$ & 27.32 \\
\hline $10: 30$ & 25.07 & $11: 00$ & 24.90 & $22: 30$ & 27.01 & $23: 00$ & 27.37 \\
\hline $11: 30$ & 23.15 & $12: 00$ & 23.03 & $23: 30$ & 27.02 & $0: 00$ & 27.29 \\
\hline
\end{tabular}

\section{Research on Distribution Network Operation of Smart City Energy Internet}

\subsection{Loss Analysis of Distributed Energy into Distribution Network}

The $10 \mathrm{kV}$ distribution network in Disney Park is taken as load, double-loop network mode is adopted for power supply with high reliability. The incoming cable models of switch stations are $400 \mathrm{~mm} 2$, and the outgoing cable models are $240 \mathrm{~mm} 2$ and below. The system has 38 nodes and 40 branches. The nodes and branch parameters required for network calculation are shown in Table 1. The daily load data of the distribution system is shown in Table 2 , and the maximum load is about $30 \mathrm{MW}$.

an example for simulation calculation. The distributed power supply with different capacity was connected to the north, west and south switchstations of Nylonland respectively, and the influence of distributed power supply on network loss was analyzed. The specific results are shown in Table 3 and Figure 1.

Table 3. Influence of distributed power on network loss

\begin{tabular}{cccc}
\hline \multirow{2}{*}{ Access Capacity (MW) } & \multicolumn{3}{c}{ Network loss (MW) } \\
\cline { 2 - 4 } & $\begin{array}{c}\text { North switch } \\
\text { station }\end{array}$ & $\begin{array}{c}\text { West switch } \\
\text { station }\end{array}$ & $\begin{array}{c}\text { South switch } \\
\text { station }\end{array}$ \\
\hline 0 & 0.866 & 0.864 & 0.834 \\
\hline 1 & 0.839 & 0.865 & 0.804 \\
\hline
\end{tabular}




\begin{tabular}{cccc}
\hline 2 & 0.856 & 0.844 & 0.762 \\
\hline 3 & 0.836 & 0.796 & 0.773 \\
\hline 4 & 0.843 & 0.851 & 0.726 \\
\hline 5 & 0.861 & 0.792 & 0.792 \\
\hline 6 & 0.865 & 0.838 & 0.83 \\
\hline 7 & 0.837 & 0.846 & 0.818 \\
\hline
\end{tabular}

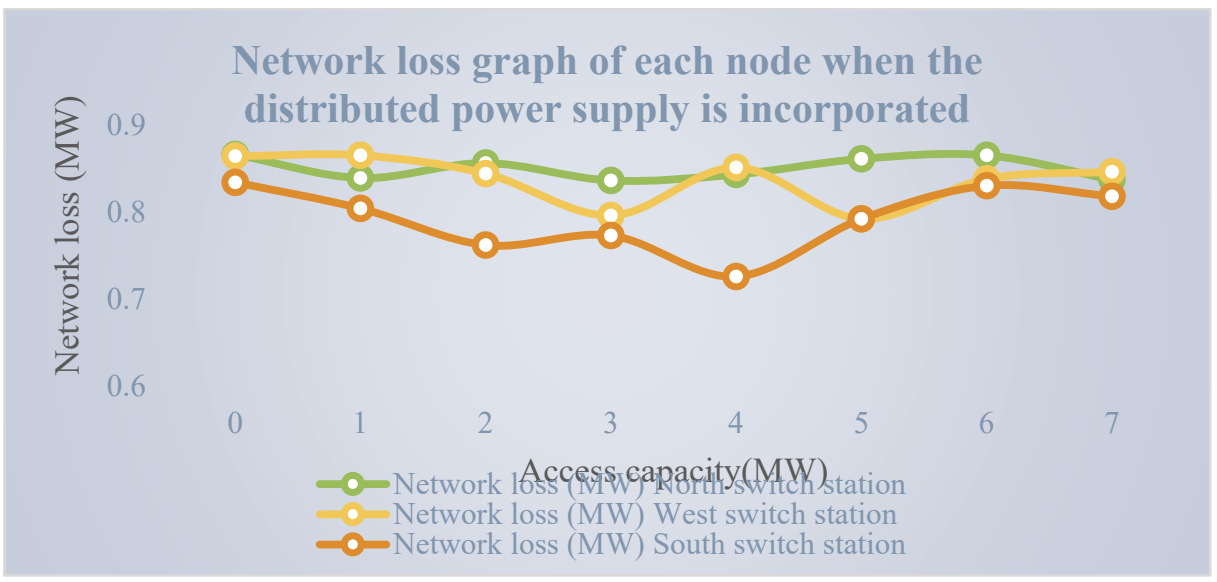

Figure 1. Network loss curve of each node when the distributed power supply is incorporated

It can be seen from the feedback data in the table and figure that after the bus in The North switch station of Disneyland was connected to the distributed power supply, the network loss first fell and then rose with the increase of the capacity of the distributed power supply, and the change curve was a wave curve. When the access capacity was about $3 \mathrm{MW}$, the network loss reached the minimum value of $0.836 \mathrm{MW}$.

The results of the above case analysis show that :(1) The integration of distributed power supply in the distribution network node can reduce the network loss; (2) The combination of distributed power supply with different nodes can effectively reduce the network loss. According to the increase of grid-connection capacity, the network loss value will be reduced to the minimum, and then gradually increase to become an upward parabola; (3) In the context of the energy Internet, a variety of distributed energy resources can be selected. In the formulation of operation mode, the output of distributed power supply can be arranged in the way with minimum network loss, so as to achieve the purpose of economic operation of power grid.

\subsection{Load Curve Analysis of Distributed Energy into the Distribution Network}

In the case of high, low and unbalanced power load, a prominent problem in operation is the large peak-valley difference. The calculated load curve is shown in Figure 2.

\section{Grid-connected power improves load graph}

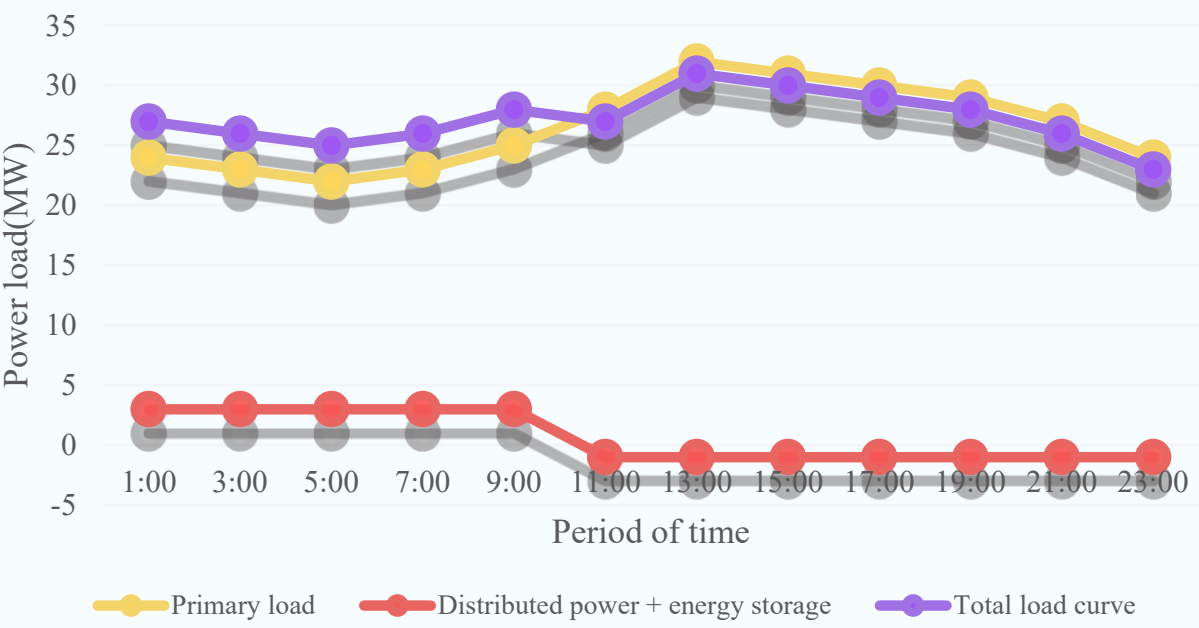

Figure 2. Load curve of grid-connected power improvement 
Feedback information from the chart, the combination of the distributed energy generation and energy storage device may fill in peak and low load adjustment, greatly reduce the system peak valley, raised some thermal power, nuclear power unit operation condition, steady output of the unit, often don't have to increase or decrease the output or switch unit in the operation, reduces the operation of the traditional coal-fired power plants and power input, to some extent, reduce the accident rate of the operation.

\subsection{Improvement Strategies for Distribution Network Regulation and Operation under the Background of Smart City Energy Internet}

In the context of the energy Internet, the interconnection of multiple distributed power sources not only improves energy utilization efficiency, but also brings a series of problems to protection. In order to solve these problems, the following protection strategies can be adopted:

(1) Steady state process

The first is the influence on the steady-state current. Near the junction point, it mainly affects the load current of the upstream branch. When the amount of merger increases, the load current of the superior branch presents a downward trend. Followed by the over current protection setting values of check, due to the superior branch of load current affected by the distributed power grid capacity increase and decrease, the superior branch of the over current setting value must be based on increased with the amount of absorbed into lower, refusing action, otherwise may be produced and the downstream branch and phase in the branch will not be affected by this.

(2) Transient process

The first is the influence on the fault current. In the case of short circuit, the fault current increases obviously at the lower level due to the interconnection of the short circuit point, and when the fault occurs at the lower level, partial fault current is provided so that the fault current value of the higher level decreases gradually. Secondly, due to the change of the fault current, the protection may have problems of misoperation and misoperation on the basis of the original setting value. Therefore, it is necessary to fully consider its influence on relay protection caused by rejection and misoperation when the power is connected to the grid, check the protection setting value timely according to the multi-power mode, and limit the merging amount according to the need to ensure the reliability of protection action.

(3) Configure protection

For the distributed energy access under the complicated wiring mode of distribution network, it is impossible to meet the requirements only by adjusting the protection fixed value and limiting the distributed power capacity. In order to ensure the safe operation of the system, it is suggested to configure protection as follows: First, the lines from transformer to distributed power supply path are configured with fiber longitudinal differential protection, and backup direction of overcurrent and zero current protection belt; Second, the self-cutting start of substation and switch station should be coupled to the corresponding small power line; Third, if the short circuit current provided by the distributed power supply is greater than the rated value of primary equipment on each side of the main transformer, overcurrent protection on the low-voltage side of the multi-voltage blocking transformer should be configured. Fourth, zero voltage protection or optical fiber longitudinal differential protection should be installed on the HV side of the main transformer.

\section{Conclusion}

The energy Internet has brought new opportunities and challenges to the regulation and operation management of distribution networks. Under this background, how to improve the regulation and management level of power grids and ensure the security of urban power grids is an urgent problem to be solved. Based on investigating the domestic and international relevant research results and a large number of simulation calculation on the basis of the research on the above issues, the study suggests that distributed new energy for the scheduling of a weakness, it enriched the means of regulation, can support the node voltage during the fault, but because of the uncertainty of the renewable energy affect system safe operation, can limit the power into the distribution network capacity or adjustment to compensate for the network connection mode; in the choice of operation mode, the network loss of the system can be optimized by adjusting the connection point and grid-connected capacity of distributed power supply, the economy of the system can be improved under the condition of safety constraints, and the purpose of smoothing load curve can be achieved by the coordination of distributed power supply and energy storage device.

\section{References}

1. Qi Q, Wu J, Long C. (2017) Multi-objective operation optimization of an electrical distribution network with soft open point. Applied Energy, 208(dec.15):734-744.

2. Chen Y, Wei W, Liu F, et al.(2019) Energy Trading and Market Equilibrium in Integrated Heat-Power Distribution Systems. Smart Grid, IEEE Transactions on, 10(4):4080-4094.

3. Liu W, Niu S, Xu H. (2017) Optimal planning of battery energy storage considering reliability benefit and operation strategy in active distribution system[J]. Journal of Modern Power Systems and Clean Energy, 5(2):177-186.

4. Wang Q, Liao J, Su Y, et al. (2018) An optimal reactive power control method for distribution network with soft normally-open points and controlled air-conditioning loads. International Journal of Electrical Power \& Energy Systems, 103(dec.):421-430.

5. Ibrahim K A, Au M T, Gan C K, et al. (2017) System wide MV distribution network technical losses estimation based on reference feeder and energy flow model. International journal of 
electrical power and energy systems, 93(dec.):440450.

6. Biswas P P, Mallipeddi R, Suganthan $\mathrm{P} N$, et al.(2017) A multiobjective approach for optimal placement and sizing of distributed generators and capacitors in distribution network. Applied Soft Computing, 60:268-280.

7. Jiang T, Li Z, Jin X, et al.(2018) Flexible operation of active distribution network using integrated smart buildings with heating, ventilation and airconditioning systems[J]. Applied Energy, 226(SEP.15):181-196.

8. Baraffe H D, Cosson M, Bect J, et al. (2018) A novel non-intrusive method using design of experiments and smooth approximation to speed up multi-period load-flows in distribution network planning. Electric power systems research, 154(jan.):444-451.

9. Fontana N, Giugni $M$, Glielmo L, et al. (2019)Operation of a Prototype for Real Time Control of Pressure and Hydropower Generation in Water Distribution Networks. Water Resources Management, 33(2):697-712.

10. Petinrin J O, Shaaban M. (2019) Multiperiod Coordination of Local Voltage Controllers and Energy Storage for Voltage Regulation in Distribution Feeder-Connected Renewable Energy Sources. Iranian Journal of Science and Technology, Transactions of Electrical Engineering, 43(3):531-544. 